\title{
Nitric Oxide Supplementation Ameliorates Dextran Sulfate Sodium-Induced Colitis in Mice
}

\author{
Azucena Salas, Meritxell Gironella, Antonio Salas, Antonio Soriano, Miquel Sans, \\ Juan lovanna, Josep M. Piqué, and Julián Panés
}

Department of Gastroenterology (Azucena Salas, MG, Antonio Soriano, MS, JMP, JP), Institut de Malalties Digestives, Hospital Clínic, Institut d'Investigacions Biomèdiques August Pi i Sunyer (IDIBAPS), Barcelona, and Department of Pathology (Antonio Salas), Hospital Mutua of Terrassa, Barcelona, Spain; and Unité 315 INSERM (JI), Marseille, France

SUMMARY: Nitric oxide (NO) synthesis is up-regulated in inflammatory bowel disease. However, its role in the pathophysiology of this condition is controversial. The aims of this study were to assess whether nitric oxide administration ameliorates experimental colitis and to determine the possible mechanisms underlying its effects on intestinal inflammation. For this purpose, the NO donor diethylamine NONOate (DETA/NO; 0.01, 0.1, 1, 5, or $10 \mathrm{mg} / \mathrm{kg} /$ day), or the DETA moiety, was administered daily to mice with dextran sulfate sodium-induced colitis. Daily body weight and colonic pathologic alterations at Day 10 were determined. Leukocyte endothelial cell interactions in colonic venules were assessed with intravital microscopy, and expression of endothelial cell adhesion molecules was determined using radiolabeled antibodies. IL-12 and IFN- $\gamma$ production were measured in intestinal tissue. Colitis induced a significant loss of body weight, reduction of colon length, and increase in colon weight and myeloperoxidase activity. Administration of $1 \mathrm{mg} / \mathrm{kg} /$ day DETA $/ \mathrm{NO}$ significantly attenuated these pathologic changes. The marked increase in leukocyte rolling and adhesion in colonic venules of colitic mice were significantly reduced by administration of $1 \mathrm{mg} / \mathrm{kg} /$ day DETA/NO. Development of colitis was associated with a marked increase in endothelial expression of intercellular adhesion molecule-1, vascular cell adhesion molecule-1, and P-selectin. Supplementation with NO significantly attenuated the up-regulation of endothelial intercellular adhesion molecule-1 and P-selectin, but not vascular cell adhesion molecule-1, in colonic tissue. NO abrogated the increase in IL-12 and IFN- $\gamma$ mRNA expression in the colon of colitic mice. The DETA moiety alone did not have any effect on any of the parameters studied. In conclusion, exogenous NO supplementation significantly ameliorates dextran sulfate sodium-induced colitis. This effect is related to a reduction in leukocyte recruitment and proinflammatory cytokine production. (Lab Invest 2002, 82:597-607).

$T$ he proposal of a potential role of nitric oxide (NO) in the pathophysiology of inflammatory bowel disease (IBD) has aroused much discussion, and evidence for and against the cytotoxicity of NO in this pathologic process has been produced. It is difficult to conclude from the existing literature whether the presence of NO on the inflamed colon participates in the progression of the inflammatory response and tissue damage or whether it has a beneficial effect, preserving the mucosa and preventing leukocyte recruitment towards the intestinal tissue.

NO production by constitutive forms of NO synthase (NOS) is critical to the maintenance of tissue and vasculature integrity, neurotransmission, and motility in the gastrointestinal tract under physiologic conditions (Lefer and Lefer, 1999; Stark and Szurszewski, 1992). It is well recognized that inducible NOS (iNOS)

\section{Received January 22, 2002.}

Supported by grant SAF00/0057 from Ministerio de Ciencia y Tecnología (to JP) and grant AP99-46726329 from Ministerio de Educación y Cultura (to $M G$ ).

Address reprint requests to: Dr. Julián Panés, Gastroenterology Department, Hospital Clinic, Villarroel 170, 08036 Barcelona, Spain. E-mail: panes@medicina.ub.es activity (Boughton-Smith et al, 1993; Rachmilewitz et al, 1995a), along with nitrite and citrulline concentrations (Middleton et al, 1993; Rachmilewitz et al, 1995a), is increased in ulcerative colitis and Crohn's disease. Immunolocalization of iNOS in ulcerative colitis and Crohn's disease occurs in foci of inflammation and is associated with goblet cell depletion and ulceration (Boughton-Smith et al, 1993).

To assess the role of NO in the pathophysiology of IBD, the in vivo effects of NO synthesis inhibition have been extensively studied in various models of experimental colitis. Inhibition of NO production using the nonspecific NOS inhibitor $\mathrm{N}^{\mathrm{G}}$-nitro-L-arginine methyl ester has produced ambiguous results. Indeed, authors have reported significant amelioration (Hogaboam et al, 1995; Rachmilewitz et al, 1995b), no protection (Conner et al, 2000), and even further exacerbation (Pfeiffer and Qiu, 1995) in various colonic inflammatory parameters including macroscopic alterations, tissue myeloperoxidase (MPO) activity, or histologic changes. Moreover, in a model of spontaneous chronic colitis in the rhesus monkey, which closely resembles IBD in humans, administration of selective inhibitors of iNOS activity did not provide any therapeutic benefit in terms of macroscopic damage and diarrhea status (Ribbons et al, 1995). Evidence shows 
that genetically modified mice that specifically lack the iNOS gene develop a more severe colitis than wildtype mice in response to acetic acid (McCafferty et al, 1997) or trinitrobenzene sulfonic acid instillation (McCafferty et al, 1999); this supports the view that NO may play a potential protective role in the inflammatory response during flares of IBD.

Exogenous NO supplementation has been proved to prevent leukocyte-endothelial cell interactions and microvascular dysfunction in different models of intestinal inflammation; this anti-inflammatory effect seems to be related, at least in part, to modulation of expression of different adhesion molecules (Lefer and Lefer, 1999). There is also a growing body of evidence supporting a key role for IL-12 in the pathogenesis of a variety of $\mathrm{T}$ helper 1-driven inflammatory responses in the intestine, including dextran sulfate sodium (DSS)-induced experimental colitis in mice (Neurath et al, 1995), and NO has been shown to downregulate IL-12 synthesis by macrophages in vitro (Huang et al, 1998). Furthermore, in a recent study, Wallace and collaborators demonstrated an enhanced anti-inflammatory effect of NO-releasing mesalamine, compared with the conventionally used 5-aminosalicylic acid molecule, in the treatment of experimental IBD (Wallace et al, 1999).

Based on these observations, we hypothesized that supplementation of colitic mice with exogenous NO could be beneficial in reducing the inflammatory response in the colonic tissue. We explored the mechanistic basis of this potential effect by studying the effects of NO supplementation on endothelial adhesion molecule expression, leukocyte-endothelial cell interactions, and proinflammatory cytokine production in the intestine.

\section{Results}

\section{Clinic and Colonic Inflammatory Parameters}

DSS-induced colitis in mice $(n=22)$ provoked a significant loss in body weight that was maximal at Days 7 and 8 after the induction of colitis $(7.8 \pm 2.27 \%$ body weight loss). After Day 8 most mice started to regain weight and showed a percentage of body weight loss at Day 10 of $2.87 \pm 3.2 \%$. Administration of a daily dose of the NO donor diethylamine NONOate (DETA/NO) $(1 \mathrm{mg} / \mathrm{kg} ; n=21)$ attenuated the percentage of body weight loss in DSS-colitic mice (Fig. 1A), whereas administration of the same dose of the DETA moiety alone $(n=16)$ did not. Significant differences in body weight loss between PBS-treated and DETA/NO-treated colitic mice were observed from Day 7 after the induction of colitis and maintained until the end of the study (Day 10). By contrast, no differences in the reduction of body weight were observed between PBS-treated mice and those receiving the DETA moiety alone. Other doses of DETA/NO tested $(0.01,0.1,5$, and $10 \mathrm{mg} / \mathrm{kg} /$ day $)$ did not significantly influence body weight loss (Fig. 1B). Treatment with DETA/NO did not affect exposure to DSS; in all treatment groups, water consumption during DSS administration was similar, ranging from 4.2 to $5.9 \mathrm{ml} / \mathrm{mice} /$ day.

Compared with controls $(n=10)$, DSS-induced colitic mice treated with PBS or with DETA alone $(n=$ 12) had a significant increase in colon weight and a decrease in colon length at Day 10 after the induction of colitis (Fig. 2). Administration of DETA/NO $(1 \mathrm{mg} /$ $\mathrm{kg} /$ day) to colitic animals resulted in a prevention of the increase in colon weight and the decrease in colon length relative to control animals (Fig. 2). Treatment with other doses of DETA/NO had no significant effect on colon weight and length in colitic mice (data not shown). The significant beneficial effects of treatment with DETA/NO at the dose of $1 \mathrm{mg} / \mathrm{kg}$ on the aforementioned colonic parameters and the wasting syndrome was consistently confirmed in additional groups of animals studied to define the mechanisms of action of DETA/NO.

At the histologic level, DSS colitis was characterized by the appearance of mucosal erosions, acute and chronic inflammatory infiltrates, crypt loss and distortion, and epithelial hyperplasia, as evaluated by a blind observer following previously described criteria (Cooper et al, 1993). A significant increase in MPO activity in colonic tissue was also demonstrated. Although the histologic score was not significantly ameliorated by NO supplementation (vehicle: $57 \pm 15$, DETA alone: $63 \pm 8$, DETA/NO $1 \mathrm{mg} / \mathrm{kg}: 48 \pm 11$ ), MPO activity was significantly reduced by treatment with DETA/NO at doses of 0.1 and $1 \mathrm{mg} / \mathrm{kg}$ but not by administration of the DETA moiety alone (Fig. 3).

\section{Nitrite Levels in Plasma}

In vehicle-treated colitic animals, plasma nitrite/nitrate levels were significantly higher than in noncolitic mice $(23.8 \pm 1 \mu \mathrm{M}$ vs $14.4 \pm 1 \mu \mathrm{M}, p<0.05)$. Administration of DETA/NO to colitic mice at the dose that produced significant amelioration of colitis ( $1 \mathrm{mg} / \mathrm{kg} /$ day) significantly increased plasma nitrite/nitrate levels $(30 \pm 2$ $\mu \mathrm{M}, p<0.05)$ relative to the vehicle-treated colitic group, whereas lower doses of DETA/NO $(0.01 \mathrm{mg} /$ $\mathrm{kg} /$ day and $0.1 \mathrm{mg} / \mathrm{kg} /$ day) produced nonsignificant changes in plasma nitrite levels $(22.48 \pm 3 \mu \mathrm{M}$ and $25.88 \pm 2 \mu \mathrm{M}$, respectively). Administration of higher doses of $\mathrm{NO}(5 \mathrm{mg} / \mathrm{kg} /$ day and $10 \mathrm{mg} / \mathrm{kg} /$ day $)$ further and significantly $(p<0.05)$ increased plasma nitrate levels in colitic mice $(60 \pm 10 \mu \mathrm{M}$ and $71 \pm 12 \mu \mathrm{M}$, respectively) relative to animals treated with 1 $\mathrm{mg} / \mathrm{kg} /$ day.

\section{Endothelial Adhesion Molecule Expression in Colitis: Effect of NO Treatment}

Because maximum differences between those animals receiving DETA/NO or placebo were observed at Day 7 after DSS induction of colitis, this was the time point chosen for evaluation of adhesion molecule expression. Values for colon endothelial surface area per gram of tissue, estimated from endothelial binding of intercellular adhesion molecule (ICAM)-2, were similar in control mice and colitic animals treated with 

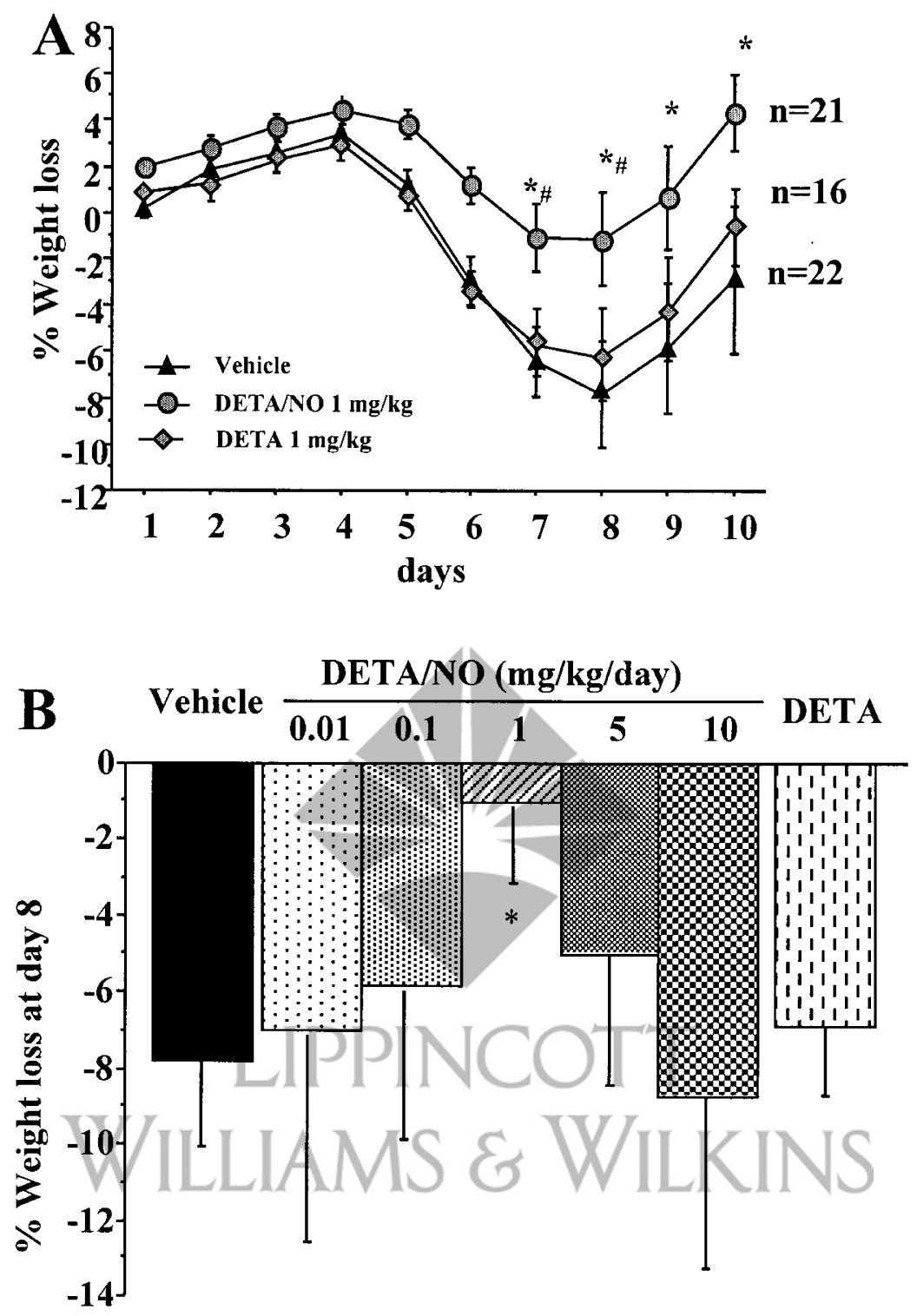

Figure 1.

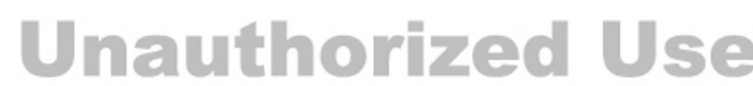

Effect of treatment with diethylamine NONOate (DETA/NO), vehicle, or the DETA moiety on dextran sulfate sodium (DSS)-induced colitis. A, Treatment with 1 $\mathrm{mg} / \mathrm{kg} / \mathrm{day}$ of DETA/NO significantly attenuated the reduction in body weight after induction of colitis from Day 7 up to the end of the study. B, Weight loss at Day 8 in colitic animals receiving various doses of DETA/NO. Significant decrease in body weight loss is only observed in the group receiving $1 \mathrm{mg} / \mathrm{kg} / \mathrm{day}$. The DETA moiety $(1 \mathrm{mg} / \mathrm{kg} / \mathrm{day})$ was without effect. * $p<0.05$ vs vehicle-treated colitic mice.

vehicle or DETA/NO (Table 1). Therefore, values for endothelial binding of antibodies against ICAM-1, vascular cell adhesion molecule (VCAM-1), P-selectin, or E-selectin were not corrected for changes in endothelial surface area relative to organ weight that might result from edema or capillary recruitment in colitic animals.

Seven days after the induction of colitis, vehicletreated mice showed a significant up-regulation in the endothelial expression of P-selectin, ICAM-1, and VCAM-1 in the cecum and distal colon, as compared with control mice (Table 1). E-selectin endothelial expression, which was absent under baseline conditions, was not increased within 1 week after induction of colitis (data not shown). Supplementation of colitic mice with DETA/NO significantly decreased P-selectin and ICAM-1 up-regulation in the colonic microvasculature (Table 1), whereas administration of DETA alone $(n=4)$ did not modify the expression of these adhesion molecules compared with vehicle-treated colitic mice (ICAM-1: $756 \pm 71$ vs $838 \pm 81 \mathrm{ng} / \mathrm{gm}$ tissue, P-selectin: $78 \pm 8$ vs $62 \pm 9 \mathrm{ng} / \mathrm{gm}$ tissue, respectively). Supplementation of colitic mice with DETA/NO had no significant effect on VCAM-1 up-regulation associated with colitis (Table 1).

It is noteworthy that $\mathrm{P}$-selectin and VCAM-1 colonic expression significantly correlated with the percentage of body weight loss. P-selectin $(r=0.97, p<0.01)$ 

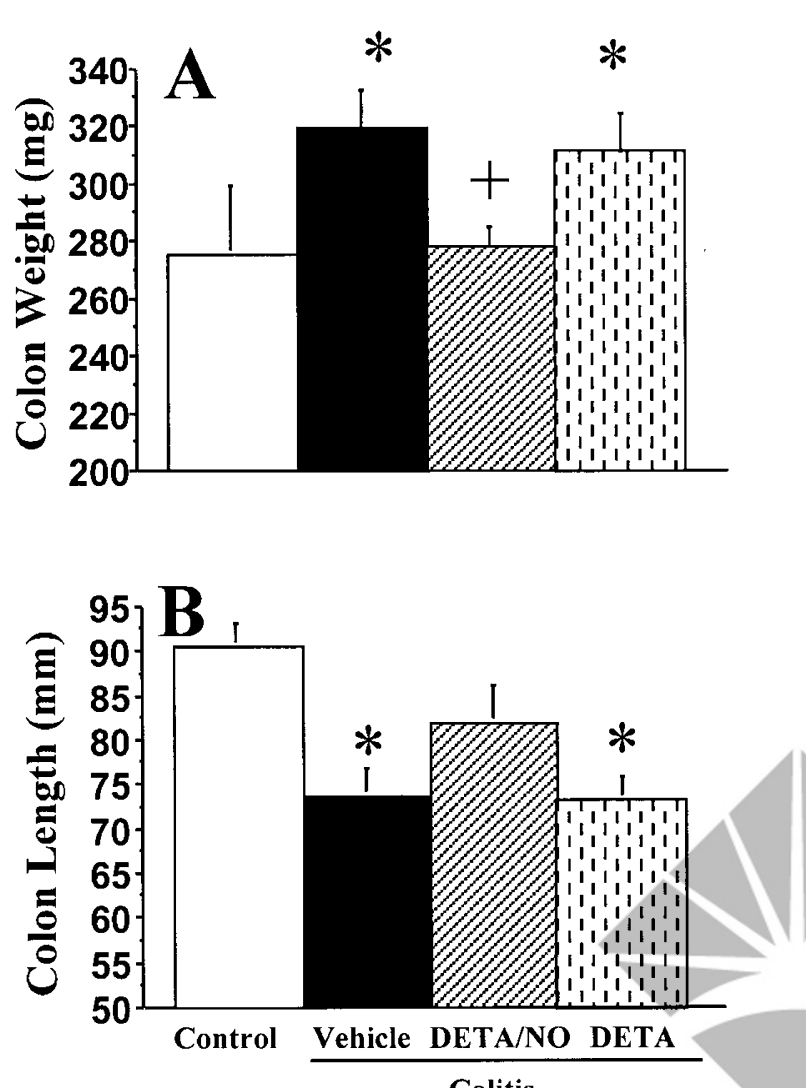

Figure 2.

Colon weight $(A)$ and length (B) in control animals and colitic mice treated with vehicle, DETA/NO $1 \mathrm{mg} / \mathrm{kg} /$ day, or the DETA moiety $1 \mathrm{mg} / \mathrm{kg} /$ day. Administration of the NO donor, but not DETA, significantly reduced the increase in colon weight in colitic mice and prevented the reduction in colon length. ${ }^{*} p<0.05$ vs control noncolitic mice; $+p<0.05$ vs vehicle-treated colitic mice.

and VCAM-1 $(r=0.95, p<0.01)$ expression was maximal in those animals exhibiting a higher body weight loss, in vehicle and NO-treated animals.

\section{Leukocyte-Endothelial Cell Interactions in Colonic Venules: Effect of NO Treatment}

Observation of colonic venules from colitic animals by intravital microscopy at Day 7 after colitis induction revealed a significant increase in the flux of rolling leukocytes, as well as a significant decrease in their rolling velocity, compared with control mice(Fig. 4, A and B). Treatment of colitic mice with DETA/NO attenuated the increase in leukocyte rolling flux and restored leukocyte rolling velocity to levels similar to those of control mice (Fig. 4, A and B). More importantly, the marked increase in leukocyte adhesion present in venules of colitic mice was significantly reduced by treatment with the NO donor, whereas treatment with the DETA moiety alone did not have any effect on these parameters (Fig. 4C).

To test whether the decrease in ICAM-1 and P-selectin expression as a result of treatment with DETA/NO can be implicated in the attenuation of leukocyte-endothelial cell interactions in colonic

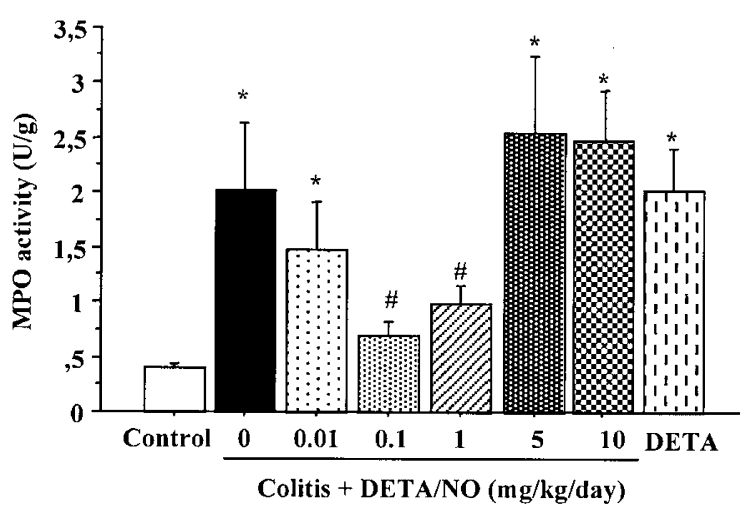

Figure 3.

Myeloperoxidase (MPO) activity in colonic tissue of control mice and colitic mice treated with different doses of DETA/NO or the DETA moiety. Induction of colitis induced a significant increase in MPO activity in colonic tissue. Treatment with 0.1 and $1 \mathrm{mg} / \mathrm{kg} /$ day of DETA/NO significantly reduced MPO activity, whereas $1 \mathrm{mg} / \mathrm{kg} /$ day DETA did not affect MPO activity. ${ }^{*} p<0.05$ vs control noncolitic mice. \# $p<0.05$ vs vehicle-treated colitic mice.

Table 1. Endothelial Adhesion Molecule Expression in Colon: Effects of NO Treatment Results are expressed as specific binding of antibody in ng/gm tissue

\begin{tabular}{lccc}
\hline & Control & Colitis + vehicle & Colitis + DETA/NO \\
\hline ICAM-2 & $340 \pm 25$ & $396 \pm 32$ & $334 \pm 34$ \\
ICAM-1 & $218 \pm 4$ & $838 \pm 81^{a}$ & $490 \pm 79^{a, b}$ \\
VCAM-1 & $36 \pm 4$ & $158 \pm 27^{a}$ & $198 \pm 38^{a}$ \\
P-selectin & $3 \pm 1$ & $62 \pm 9^{a}$ & $29 \pm 9^{a, b}$ \\
\hline
\end{tabular}

${ }^{a} p<0.05$ vs. Control.

${ }^{b} p<0.05$ vs. colitis + vehicle.

NO, nitric oxide; ICAM, intercellular adhesion molecule; VCAM, vascular cell adhesion molecüle; DETA/NO, diethylamine NONOate.

venules during colonic inflammation, we treated colitic animals with blocking anti-ICAM-1 and anti-P-selectin antibodies. The flux of rolling leukocytes was significantly reduced in colitic animals treated with these antibodies $(73 \pm 11$ vs $25 \pm 5$ cells/minute, $p<0.01)$, but the adhesive response was the same as in colitic animals not receiving the antibodies ( $4.6 \pm 0.4$ vs 4.6 \pm 0.8 cells $/ 100 \mu \mathrm{m}, p=\mathrm{NS}$ ).

\section{Proinflammatory Cytokine Production}

Plasma levels of IL-12 were undetectable in both control or colitic animals as measured by ELISA. Levels of IL-12 protein in colonic samples of control and colitic mice were measured by Western blot, and Figure 5A shows representative bands. The presence of three distinct bands of the IL-12 dimer is consistent with variable glycosylation of the monomer as has been previously described (Heinzel et al, 1997). Interestingly, some IL-12 protein was detected in control mice. The mean optical density ratio of control mice ( $n$ $=2$ ) was taken as 1 , and each band was expressed as a fold increase of this mean. Figure $5 \mathrm{~B}$ shows that the mean fold increase for colitic mice $(n=3)$ was 2.5 and that treatment with exogenous NO $(n=3)$ yielded IL-12 levels similar to those of noncolitic mice. 

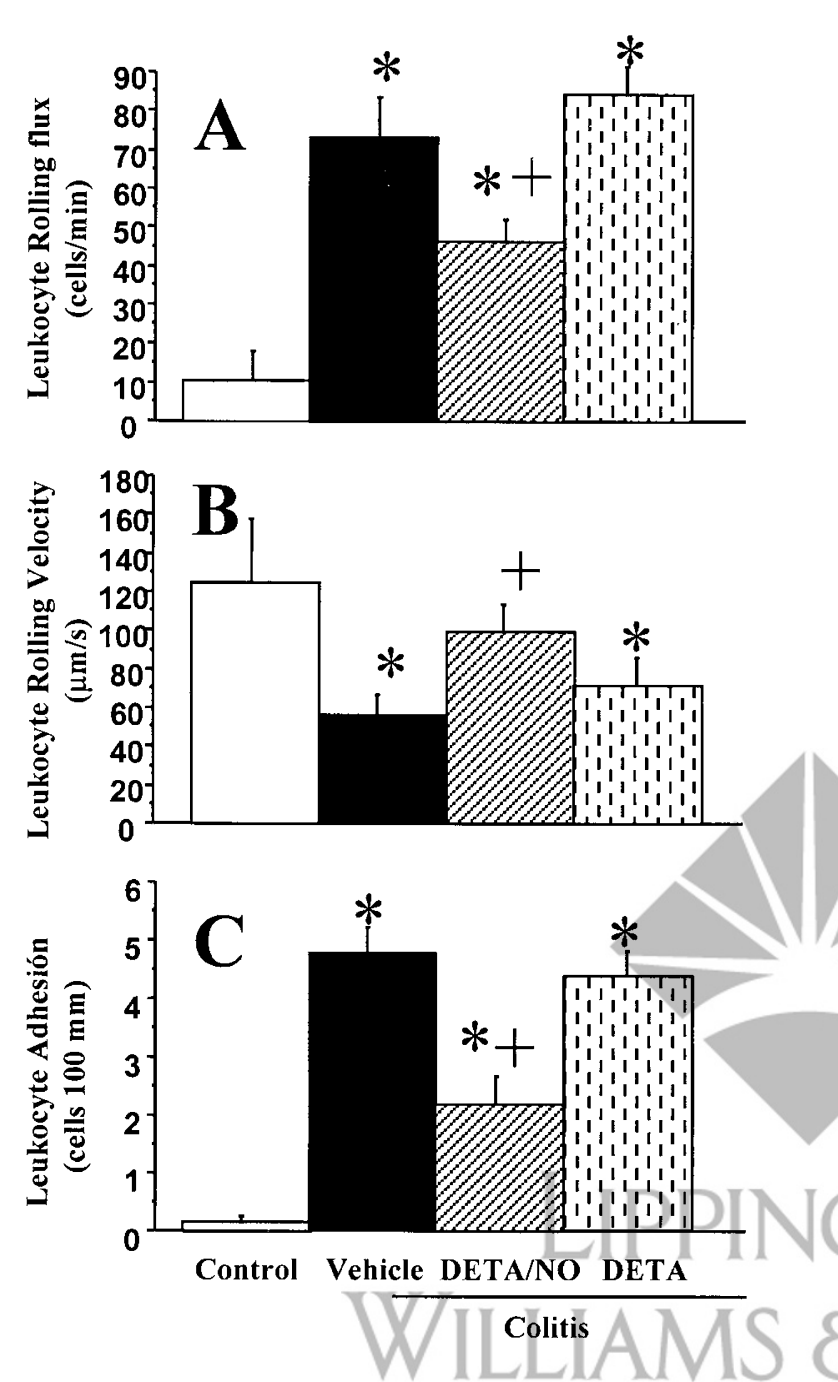

Figure 4.

Leukocyte-endothelial cell interactions in colonic venules. Colitis is associated with a marked increase in the flux of rolling leukocytes $(A)$, a reduction in rolling velocity (B), and an increase in firm leukocyte adhesion (C). Treatment with $1 \mathrm{mg} / \mathrm{kg} /$ day of DETA/NO significantly reduced rolling and firm adhesion interactions. ${ }^{*} p<0.05$ vs noncolitic mice; $+p<0.05$ vs vehicle-treated colitic mice.

The increase in IL-12 protein levels in colitic animals was associated with an increase in IL-12 mRNA as measured by semiquantitative RT-PCR. Again, basal mRNA expression of both IL-12 subunits (p40 and p35) was detected in colonic samples from control animals. IL-12 p40 and p35 mRNA levels increased significantly in colitic mice, and this increment was abrogated in animals treated with DETA/NO (Fig. 6A). In colitic animals, the severity of colitis assessed as reduction in body weight relative to basal, significantly correlated with the fold induction in IL-12 ( $r=0.88, p$ $<0.02)$. IFN- $\gamma$ message levels changed in parallel with IL-12, with significant increments in colitic mice relative to controls (Fig. 6B). A highly significant correlation was observed between IL-12 and IFN- $\gamma$ message levels in animals with DSS-induced colitis $(r=0.93, p$ $<0.01)$. Treatment of colitic mice with DETA-NO resulted in a significant reduction of IFN- $\gamma$ message levels in colonic tissue (Fig. 6B).
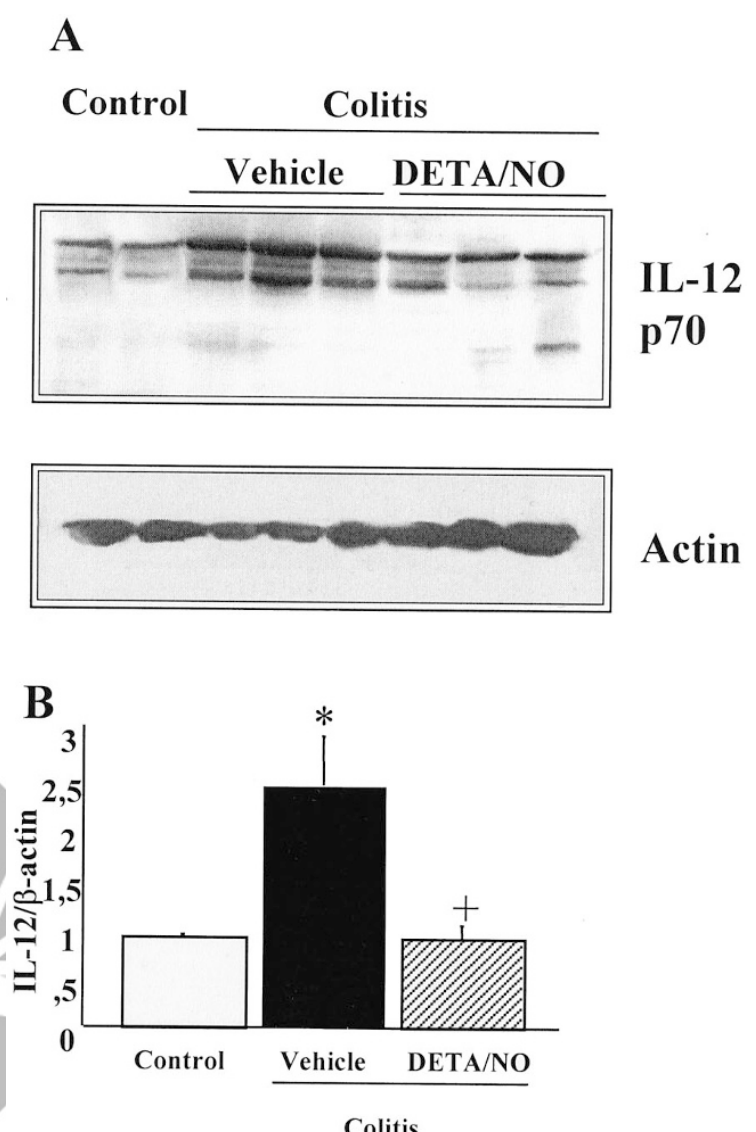

Figure 5.

A, Measurement of IL-12 p70 heterodimer expression by Western blotting in colonic protein samples from control mice $(n=2)$ and vehicle-treated $(n=3)$ or $1 \mathrm{mg} / \mathrm{kg} /$ day DETA/NO-treated $(n=3)$ colitic mice. The immunoblot was hybridized with an anti-mouse IL-12 p70 heterodimer antibody. Detection with an anti-actin antibody was used as an internal marker. B, Mean data after analysis of the IL-12 p70 band intensity expressed as a ratio of the actin band for the various groups. The intensity of IL-12 p70 band in control mice was equated to 1; other bands were expressed as a fold increase over this level. Weak bands are observed in control animals, and a 2.5-fold increase in band intensity appears after induction of colitis. Treatment with DETA/NO reduces IL-12 p70 levels to those of control mice. ${ }^{*} p<0.05$ vs control noncolitic mice. $\pm p<0.05$ vs vehicle-treated colitic mice.

\section{Discussion}

NO donors have been extensively used in experimental models of inflammation with striking benefits on prevention of leukocyte adhesiveness and migration as well as microvascular barrier preservation. Antiinflammatory actions of NO include regulation of adhesion molecule expression, prevention of platelet aggregation, stimulation of cGMP synthesis, modulation of iron-catalyzed oxidation reactions, and inhibition of lipid peroxidation (Lyons, 1995). NO has been shown to have a direct cytoprotective effect on endothelial, vascular smooth muscle, or splanchnic visceral cells controlling microvascular permeability (Aoki et al, 1990). NO also participates in the control of the immune response and in mucosal defense and repair in the gastrointestinal tract (Whittle, 1997). However, because NO production is enhanced in IBD, limited effort has been devoted to explore the potential ben- 

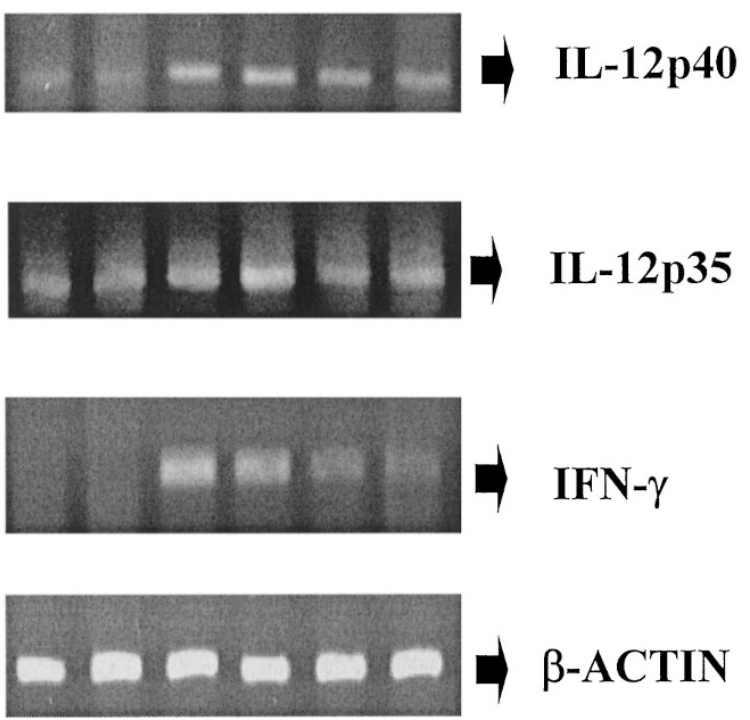

$\overline{\text { Control }} \overline{\text { Vehicle }} \overline{\text { DETA/NO }}$

Colitis

Figure 6.

A representative $2 \%$ agarose gel of RT-PCR products. IL-12 (p40 and p35 subunits), IFN- $\gamma$, and $\beta$-actin (internal marker) RT-PCR products are shown for colonic tissue taken from control $(n=2)$, vehicle-treated $(n=2)$, or DETA/NO-treated $(n=2)$ colitic mice. Vehicle-treated colitic mice have higher expression of mRNA for IL-12p40, IL12p35, and IFN- $\gamma$ than control mice. Treatment with $1 \mathrm{mg} / \mathrm{kg} /$ day DETA/NO reduces the levels of mRNA expression of these cytokines compared with vehicle-treated colitic mice.

eficial effect of $\mathrm{NO}$ administration during the course of colonic inflammation.

The current study confirms that in the DSS-induced model of colitis, there is a significant increase in plasma NO metabolites (nitrite/nitrate) às compared with control animals. Administration of DETA/NO, at a dose that increased plasma nitrite concentrations (1 $\mathrm{mg} / \mathrm{kg} /$ day) in colitic mice, significantly reduced the wasting syndrome associated with DSS-induced colitis, reducing body weight loss and ameliorating pathologic colonic changes (ie, increase in colon weight and colon shortening) that correlate with the severity of colitis in this experimental model. Although treatment with exogenous NO did not significantly modify colitis histologic score, it reduced neutrophil infiltration as measured by the MPO activity. The specificity of the action of NO is shown by the lack of effect of the DETA moiety of the NO-donor molecule alone in any of the parameters of colonic inflammation.

The beneficial effect of exogenous NO supplementation was observed in only a very narrow dose range ( 0.1 to $1 \mathrm{mg} / \mathrm{kg} /$ day), with lower or higher doses being ineffective. This may explain the apparent discrepancy between our results and those of Wallace et al (1999) showing that an aspirin derivative that releases NO over a prolonged period of time did not affect the severity of trinitrobenzene sulfonic acid-induced colitis. Differences between the two studies in the model of colitis and the NO donor molecule used might also explain the discrepant observations.

The mechanism through which DETA/NO reduced the severity of colonic injury may be related to several of its actions, including attenuation of leukocyte endothelial cell interactions (Gauthier et al, 1994), prevention of microvascular fluid and protein leakage (Kubes and Granger, 1992), and attenuation of microvascular dysfunction (Kurose et al, 1994; Lefer and Lefer, 1999). The observed ability of the NO donor to diminish leukocyte rolling and adhesion in colonic postcapillary venules suggests that this could be one of the reasons for its anti-inflammatory activity in the context of colitis. Leukocyte-endothelial cell interaction is a finely regulated process governed by adhesion molecules expressed on leukocytes and endothelial cells. The results of the current study demonstrate that expression of endothelial adhesion molecules P-selectin, ICAM-1, and VCAM- 1 is markedly up-regulated in the DSS model of colitis. These results are in agreement with previous clinical and experimental studies in other models of colitis showing similar results (Nakamura et al, 1993; Sans et al, 1999). Furthermore the current study suggests that up-regulation of P-selectin and VCAM-1, but not ICAM-1, does indeed have a direct relationship to the severity of colitis, because the level of expression of these adhesion molecules strongly correlated with body weight loss. In fact, a critical role for VCAM-1mediated cellular interactions has been demonstrated in this model of experimental colitis by means of selective immunoblockade (Soriano et al, 2000).

The significant reduction in leukocyte rolling and adhesion in intestinal venules of colitic mice in response to treatment with DETA/NO was coincident with a decreased expression of P-selectin and ICAM-1. This observation is in keeping with previous evidence showing that NO may down-regulate stimulated expression of ICAM-1 (Spiecker et al, 1998) and P-selectin (Murohara et al, 1996) in vitro and also suppresses up-regulation of these adhesion molecules in vivo in response to ischemia and reperfusion (Salas et al, 1999). The lack of effect of NO supplementation on VCAM-1 expression was an unexpected result of the current study, given the existing evidence that exogenous NO donors may down-regulate cytokine-induced VCAM-1 expression in cultured endothelial cells in vitro (Spiecker et al, 1998; Takahashi et al, 1996) and the critical role of this adhesion molecule as a mediator of leukocyte adhesion in this experimental model of colitis (Soriano et al, 2000). However, a recently published in vivo study suggests that NO may not modulate VCAM-1 expression in a model of colitis, because inhibition of NO synthesis did not alter the enhanced levels of VCAM- 1 expression in colitic severe combined immunodeficiency mice reconstituted with $\mathrm{CD}^{+}, \mathrm{CD} 45 \mathrm{RB}^{\text {high }} \mathrm{T}$ cells, and VCAM-1 up-regulation in response to a high-dose of TNF- $\alpha$ is similar in wild-type mice and animals with genetic deficiency of iNOS (Kawachi et al, 1999).

The reduced P-selectin expression in colitic animals treated with DETA/NO is a plausible mechanistic explanation for the reduction in leukocyte rolling in response to exogenous NO supplementation, because treatment with an anti-P-selectin antibody reduced leukocyte rolling to a similar extent as treatment 
with DETA/NO. However, the reduction in ICAM-1 expression does not seem to be the main cause of the decreased leukocyte adhesion in DETA/NO-treated mice because immunoblockade of ICAM-1 did not affect firm leukocyte adhesion in intestinal venules. Nevertheless, immunoneutralization experiments were performed by administration of a single blocking dose of the antibodies at Day 7 after the induction of colitis, and we cannot rule out the possibility that sustained reduction in expression of $\mathrm{P}$-selectin and ICAM-1 as a result of daily administration of exogenous NO may have contributed to diminished colonic damage and neutrophil recruitment into the colon.

Among other possible molecular mechanisms that may account for the anti-inflammatory effects of NO in IBD, some seem to be of special relevance. First, NO is known to reduce nuclear factor $-\kappa B$ binding to DNA and attenuates signal-initiated degradation of $\mathrm{I}_{\kappa} \mathrm{B} \alpha$ (Chen et al, 1999), therefore inhibiting transcription of nuclear factor- $\mathrm{kB}$-dependent genes, including P-selectin, ICAM-1, and iNOS itself (Fowler et al, 1999). NO has also been shown to modulate IL-12 synthesis in vitro, because macrophage IL-12 production is markedly enhanced by $\mathrm{N}^{\mathrm{G}}$-monomethyl-L-arginine but profoundly inhibited by S-nitroso-N-acetyl-penicillamine (Huang et al, 1998), and this cytokine seems to play a central role in the pathophysiology of experimental colitis as shown by the remarkable beneficial effects of treatment with an IL-12-neutralizing antibody (Neurath et al, 1995). In the current study, we observed that treatment of colitic mice with DETA/NO induced a significant reduction of IL-12 protein and message levels in intestinal tissue of colitic mice, which was associated with a significant reduction of IFN- $\gamma$ transcription. Because $\mathrm{H}-12$ is a major inducer of T helper 1 cells, which produce IFN- $\gamma$ that activates macrophages to produce more $\mathrm{IL}-12$, these data suggest that NO may act as an inhibitor of this feedback loop, preventing excessive amplification of $\mathrm{T}$ helper 1 cells, which are implicated in the pathogenesis of DSSinduced colitis.

A potential protective role of NO in human IBD is supported by the findings of higher colonic NO induction in patients with collagenous colitis, a process with scarce inflammatory infiltration and absence of mucosal damage, than in ulcerative colitis (Lundberg et al, 1997). Although ulcerative colitis and collagenous colitis are distinct disorders, with differing etiopathogenesis, the lower NO concentrations observed in active ulcerative colitis compared with collagenous colitis may reflect impaired compensatory NO production by iNOS, in a condition characterized by increased formation of oxidant radicals.

In summary, the results of the current study demonstrate that administration of an NO donor has a significant therapeutic effect in DSS-induced experimental colitis, with a reduction in the clinical wasting syndrome and pathologic colonic alterations. These beneficial effects depend, at least in part, on the reduction in leukocyte recruitment into the inflamed colon and the inhibition of the production of a key proinflammatory cytokine such as IL-12. These re- sults, along with the observation of Wallace et al (1999) that NO-releasing mesalamine is more effective that mesalamine alone in the treatment of experimental IBD, form a rational basis for testing the administration of NO donors as adjuvant therapy in human IBD.

\section{Methods}

\section{Animal Model of Colitis}

Experimental colitis was induced in male CD1 mice weighing 28 to $30 \mathrm{gm}$ (Iffa Credo, Lyon, France) by administering 5\% (wt/vol) DSS (molecular weight 40 kd; ICN Biomedicals Inc., Costa Mesa, California) in drinking water ad libitum for 4 days. Mice were killed at Days 7 or 10 . Body weight, presence of blood in excreta, and stool consistency were determined daily.

\section{NO Administration}

DETA/NO (Calbiochem, La Jolla, California), an NO donor with a half-life of 56 hours, was administered subcutaneously once daily to colitic mice, at doses of $0.01,0.1$, 1,5 , or $10 \mathrm{mg} / \mathrm{kg}$ (12 mice per group). The first dose of DETA/NO was given 5 hours before the administration of DSS. Additional groups of colitic animals were injected daily with vehicle (PBS) or DETA alone at a dose of 1 $\mathrm{mg} / \mathrm{kg} /$ day. DETA alone was obtained by diluting the same DETA/NO in PBS at pH 7.4; this was filtered and kept in sterile conditions in a laminar flow hood for 5 days (approximately two half-lives of NO release) to allow all the NO to evaporate.

On Day 10,-animals were killed by an overdose of ketamine (Ketolar; Parke-Davis Inc., Morris Klein, New Jersey) and xylazine (Sigma, Madrid, Spain). The colon was excised and opened by a longitudinal incision, rinsed with saline, and weighed; its length was measured after exclusion of the cecum. Distal colon samples $(\cong 20 \mathrm{mg}$ ) were then excised, snap-frozen in liquid nitrogen, and stored at $-80^{\circ} \mathrm{C}$ for later assay of MPO activity, which has been previously used as a measure of neutrophil infiltration (Yamada et al, 1992). MPO activity was assessed according to the technique described by Bradley et al (1982); results are expressed as units per gram of tissue. To evaluate histologic damage, colonic samples were fixed in $4 \%$ formalin and embedded in paraffin; sections (5 to 7 $\mu \mathrm{m})$ were stained with hematoxylin and eosin following standard procedures. Stains were assessed by a single pathologist (Antonio Salas) in a blinded fashion. Colitis was graded quantitatively according to a previously defined criteria, which takes into account the extension of mucosal injury, expressed as percentage relative to total colon length, and lesion depth (Cooper et al, 1993).

\section{Measurement of Endothelial Adhesion Molecule Expression}

P-selectin, E-selectin, ICAM-1, ICAM-2, and VCAM-1 expression was measured in the following groups of mice $(n=5$ per group): control mice and DSS-induced 
colitic mice receiving either PBS or DETA/NO (1 mg/ $\mathrm{kg} /$ daily). Expression of ICAM-1 and P-selectin was also measured in additional groups of colitic mice treated with the DETA moiety of the NO donor molecule. All these studies were performed at Day 7 after induction of colitis because symptoms of colitis started to wane at this time point. ICAM-2, which is constitutively expressed on endothelial cells and is not up-regulated in response to cellular activation, was measured as an estimation of endothelial surface area relative to tissue weight.

The antibodies used were as follows: RMP-1, a murine immunoglobulin $\mathrm{G}_{2 \mathrm{a}}\left(\operatorname{lgG}_{2 \mathrm{a}}\right)$ against rat and mouse P-selectin (Walter et al, 1997); RME-1, a murine $\operatorname{lgG}_{1}$ against rat and mouse E-selectin; $Y N 1.7 .4$., a rat $\lg _{2 b}$ directed against mouse ICAM-1; 3C4, a rat $\operatorname{lgG}_{2 a k}$ against mouse ICAM-2; and $M K 1.9 .1$, a rat $\lg \mathrm{G}_{1 \kappa}$ against mouse VCAM-1. UPC10, a purified mouse IgG, was used in all experiments as a nonbinding antibody.

mAbs RMP-1, RME-1, YN1.7.4, and MK1.9.1. were scaled-up and purified by protein AVG chromatography at Pharmacia \& Upjohn Laboratories (Kalamazoo, Michigan). 3C4 and UPC10 were purchased from PharMingen (San Diego, California) and Sigma, respectively.

Binding mAbs directed against endothelial adhesion molecules were labeled with ${ }^{125} \mathrm{I}$, whereas the nonbinding mAb (UPC10) was labeled with ${ }^{131} \mathrm{I}$. Radioiodination of the mAbs was performed by the iodogen method (Fraker and Speck, 1978). The specific activity of labeled $\mathrm{mAbs}$ was $\cong 0.5 \mathrm{mCi} / \mathrm{mg}$. The following amount of mAbs were used for assessment of endothelial expression of adhesion molecules: ICAM-1: 10 $\mu \mathrm{g}$ of ${ }^{125} \mathrm{I}-\mathrm{YN} 1 / 1.7 .4$ and $40 \mu \mathrm{g}$ of unlabeled YN1/ 1.7.4; ICAM-2: $10 \mu \mathrm{g}$ of ${ }^{125} \mathrm{~J}-3 \mathrm{C} 4$ and $60 \mu \mathrm{g}$ of unlabeled 3C4; VCAM-1: $10 \mu \mathrm{g}$ of ${ }^{125} \mathrm{I}-\mathrm{MK} 1.9 .1$ and $20 \mu \mathrm{g}$ of unlabeled MK1.9.1; P-selectin: $10 \mu \mathrm{g}$ of ${ }^{125} \mathrm{I}-\mathrm{RMP}-1$; and E-selectin $10 \mu \mathrm{g}$ of ${ }^{125} \mathrm{I}-\mathrm{RME}-1$. In all cases $10 \mu \mathrm{g}$ of ${ }^{131}$ I -UPC10 was added to the injection mixture. Doses of mAbs against adhesion molecules have been proved to be saturating under stimulation conditions in previous assays (Eppihimer et al, 1996; Henninger et al, 1997). At the time of the study, anesthesia was induced as described above. The right carotid artery and right jugular vein were cannulated. The mixture of binding and nonbinding mAbs was administered through the jugular vein catheter. Blood samples were obtained through the carotid artery catheter 5 minutes after injection of the mAb mixture. Thereafter, the animals were heparinized $(1 \mathrm{mg} / \mathrm{kg}$ sodium heparin iv) and rapidly exsanguinated. Entire organs were then harvested and weighed.

${ }^{125} \mathrm{I}$ (binding $\mathrm{mAb}$ ) and ${ }^{131} \mathrm{I}$ (nonbinding $\mathrm{mAb}$ ) activities in each organ and in 100- $\mu$ l aliquots of cell-free plasma were counted in a Cobra II gamma-counter (Packard, Meridien, Australia), with automatic correction for background activity and spillover. The injected activity in each experiment was calculated by counting a $5 \mu$ l of sample of the mixture containing the radiolabeled mAbs. The accumulated activity of each mAb in an organ was expressed as nanogram of binding antibody per gram of tissue. The formula used to calculate adhesion molecule expression was as fol- lows: Endothelial expression $=\left[\left(\mathrm{cpm}^{125} \mathrm{I} \mathrm{organ}^{*} \mathrm{~g}^{-1}\right.\right.$ ${ }^{*} \mathrm{cpm}^{125}$ I injected $\left.{ }^{-1}\right)-\left(\mathrm{cpm}{ }^{131} \mid\right.$ organ $^{*} \mathrm{~g}^{-1}{ }^{*} \mathrm{cpm}$ ${ }^{131}$ I injected $\left.^{-1}\right){ }^{*}\left(\mathrm{cpm}{ }^{125} \mathrm{I}\right.$ in plasma $) /\left(\mathrm{cpm}^{131} \mathrm{I}\right.$ in plasma)] ${ }^{*}$ ng injected binding mAb.

\section{Intravital Microscopy}

Leukocyte-endothelial cell interactions in colonic venules from control and DSS-induced colitic mice were studied by fluorescence microscopy at Day 7 after induction of colitis. Colitic mice had been treated since the induction of colitis with PBS, DETA/NO (1 $\mathrm{mg} / \mathrm{kg})$, or DETA alone $(1 \mathrm{mg} / \mathrm{kg})$. Anesthesia was induced by subcutaneous injection of xylazine (7.5 $\mathrm{mg} / \mathrm{kg}$; Sigma) and ketamine $(150 \mathrm{mg} / \mathrm{kg})$. The jugular vein was cannulated, a midline abdominal incision was made, and a section of the distal colon was exteriorized for observation. Mice were placed on a steel microscope board, in a position that allowed the colon to be observed through a glass slide covering a $3.5 \times$ $3.5-\mathrm{cm}$ hole centered on the board. The steel board was placed on the stage of an inverted microscope (Diaphot 300; Nikon, Tokyo, Japan) equipped with a CF Fluor $\times 40$ objective lens (Nikon). Rectal temperature was maintained between $36.5^{\circ} \mathrm{C}$ and $37.5^{\circ} \mathrm{C}$, using an infrared heat lamp.

Leukocytes were in vivo labeled by injection of rhodamine-6G $(0.3 \mathrm{mg} / \mathrm{kg}$; Molecular Probes, Leiden, The Netherlands) through the jugular catheter. Fluorescence was visualized by epi-illumination at 510 to $560 \mathrm{~nm}$, using a 590-nm emission filter. A CCD camera (XC-77; Hamamatsu Photonics, Hamamatsu, Japan), with a C2400 CCD camera control unit and a C2400-68 intensifier head (Hamamatsu Photonics) mounted on the microscope, projected the image onto a monitor (Trinitron 14CP1; Sony, Tokyo, Japan). Images were recorded using a videocassette recorder (SR-S368E; JVC, Tokyo, Japan) and analyzed off-line. Single unbranched submucosal and lamina propria venules with diameters (D) ranging between 25 and 35 $\mu \mathrm{m}$ and a length $>100 \mu \mathrm{m}$ were studied. Three to five venules per animal were recorded. The number of rolling and adherent leukocytes was measured off-line during playback of videotaped images. A leukocyte was considered adherent to the venular wall if it remained stationary for 30 seconds or longer. Adherent leukocytes were quantified as the number per $100-\mu \mathrm{m}$ length of venule. Rolling leukocytes were defined as those white blood cells circulating at a slower velocity than free-flowing leukocytes in the same vessel. Leukocyte rolling velocity was determined from the time required for a leukocyte to traverse a $50-\mu \mathrm{m}$ distance along the length of the venule and is expressed as micrometer per second. The flux of rolling leukocytes was measured as the number of white blood cells that could be seen rolling within a small $(10 \mu \mathrm{m})$ viewing area of the vessel, using the same area throughout the experiment. The number of rolling leukocytes per $100-\mu \mathrm{m}$ venule length was calculated by dividing the leukocyte flux by the leukocyte rolling velocity. Venular blood flow was estimated from the mean of the velocity of three free-flowing 
leukocytes (ffv), using the empirical formula $\mathrm{V}_{\mathrm{bf}}=$ $\mathrm{ffv} / 1$.6. Venular wall shear rate was calculated assuming cylindrical geometry, using the newtonian definition $\gamma=8\left(\mathrm{~V}_{\mathrm{bf}} / \mathrm{D}\right)$.

\section{In Vivo Blockade of P-selectin and ICAM-1}

Because supplementation of colitic animals with NO has the potential to modulate endothelial P-selectin and ICAM-1 expression, we explored the effect of simultaneous P-selectin and ICAM-1 immunoblockade on leukocyte-endothelial cell interactions in colitic animals. We compared this effect with the effect observed in colitic mice receiving DETA/NO 1 $\mathrm{mg} / \mathrm{kg} /$ day.

For that purpose a group of colitic mice was studied at Day 7 after induction of colitis. Two doses of a mixture of anti-P-selectin (RMP-1; $10 \mu \mathrm{g}$ ) and antiICAM-1 (YN1.7.4; $50 \mu \mathrm{g}$ ) antibodies were injected intravenously at 3 hours and 30 minutes before the experiment. We pretreated the animals before the study because acute blockade of an adhesion molecule may not be able to dislodge an adherent leukocyte from the venular wall. Using intravital microscopy, leukocyte rolling and adhesion was quantified in colonic venules as described above.

\section{Nitrite Levels}

Nitrite levels were determined in plasma samples from control mice and from colitic mice receiving either PBS or DETA/NO $(0.01,0.1,1,5$, or $10 \mathrm{mg} / \mathrm{kg} /$ day $)$ at the time of study (10 days after the induction of colitis), using a colorimetric kit based on the Griess reaction (Calbiochem). These measurements were made 6 hours after administration of DETA/NO.

\section{Measurement of IL-12 Protein Levels}

Plasma IL-12 levels were measured using a commercially available kit (Endogen, Woburn, Massachusetts). Colonic protein levels of IL-12 were detected by Western blot analysis. For that purpose equal amounts of protein solution $(20 \mu \mathrm{g})$ were separated by $7.5 \%$ SDS-PAGE and transferred to nitrocellulose membranes in the presence of $20 \%$ ethanol, $25 \mathrm{~mm}$ Tris, and $192 \mathrm{~mm}$ glycine at $\mathrm{pH}$ 8.3. Nonspecific binding to the membrane was blocked by $5 \%$ nonfat dry milk in PBS-Tween 20 overnight at $4^{\circ} \mathrm{C}$. The blots were washed twice in PBS and incubated for 1 hour with an affinity-purified rat IgG anti-mouse IL-12 mAb (1:5000) directed against the heterodimer p35/p40 (Endogen). Membranes were also incubated with a mouse IgG anti-actin mAb (ICN Biomedicals), as an internal standard. Thereafter, membranes were washed with PBS-Tween 20 and incubated with the secondary antibody for 45 minutes at room temperature. After that, the membranes were washed three times (PBS-Tween 20) and developed with the ECL detection system (Santa Cruz Biotechnology, Santa Cruz, California), dried quickly, and exposed to film. Signals were quantified by scanning laser densitometry with a computing densitometer (model 300A; Mo- lecular Dynamics, Sunnyvale, California) and ImageQuant (Molecular Dynamics, Sunnyvale, California) version 3.0 software.

\section{Measurement of Cytokine mRNA Expression in Colonic Tissue}

Mice treated with PBS or DETA/NO were killed on Day 7 with an overdose of ketamine (Ketolar) and xylazine (Sigma). Distal colon samples $(\cong 100 \mathrm{mg}$ ) were then excised, snap-frozen in liquid nitrogen, and immediately processed for total cellular RNA isolation. RNA was prepared with TRIzol Reagent (Life Technologies, Grand Island, New York) following the manufacturer's instructions; concentrations were calculated from $A_{260}$ measurements. RNA integrity and loading amounts were assessed by examining $18 \mathrm{~S}$ and $28 \mathrm{~S}$ ribosomal RNA banding of samples electrophoresed in 1\% agarose gel under denaturing conditions and stained with ethidium bromide.

Analysis of IL12p40, IL12p35, and IFN- $\gamma$ mRNA expression was made by a semiquantitative RT-PCR method. $\beta$-actin mRNA expression was also measured as an internal control. In each reaction $1 \mu \mathrm{g}$ of total RNA was used with the appropriate primer pairs, and the sequence was amplified by the Life Technologies SuperScript One Step RT-PCR System according to the manufacturer's protocol. For IL12p40, the forward primer was 5'-CCAAGAACTTGCAGATGAAGCC-3' and the reverse primer was 5'-GCCAACCAAGCAGAAGACAGC-3'. For IL12p35, the forward primer was 5'-GCCAGGTGTCTTAGCCAGTC-3' and the reverse primer was 5'-CAGATAGCCCATCACCCTGT-3', For IFN- $\gamma$, the forward primer was 5'GCGTCATTGAATCACACCTG $-3^{\prime}$ and the reverse primer was 5'-CGCAATCACAGTCTTGGCTA-3'. For $\beta$-actin mRNA, the forward primer was 5'TGGAATCCTGTGGCATCCATGAAAC-3' and the reverse primer was 5'-TAAAACGCAGCTCAGTAACAGTCCG-3'. RT-PCR was performed in a thermal cycler using the following conditions: reverse transcription to CDNA, 30 minutes at $48^{\circ} \mathrm{C}$; $\mathrm{AMV}$ reverse transcriptase inactivation and RNA/cDNA denaturation, 2 minutes at $94^{\circ} \mathrm{C}$; variable number of cycles depending on the mRNA with the following phases: denaturation, 15 seconds at $94^{\circ} \mathrm{C}$; annealing, 30 seconds at $55^{\circ} \mathrm{C}$; extension, 1 minute at $72^{\circ} \mathrm{C}$; and final extension, 7 minutes at $72^{\circ} \mathrm{C}$.

Finally, amplified fragments of cDNA were resolved in $2 \%$ agarose gel electrophoresis stained with ethidium bromide. Signals were quantified by scanning laser densitometry with a computing densitometer (model 300A; Molecular Dynamics) and ImageQuant version 3.0 software.

\section{Statistical Analysis}

All data were analyzed using analysis of variance with Bonferroni as a post-hoc test and Student's paired or unpaired $t$ test where appropriate. Correlations were measured by the least square method. All values are 
reported as mean \pm SEM. Statistical significance was set at $p<0.05$.

\section{References}

Aoki N, Johnson G III, and Lefer AM (1990). Beneficial effects of two forms of $\mathrm{NO}$ administration in feline splanchnic artery occlusion shock. Am J Physiol 258:G275-G281.

Boughton-Smith NK, Evans SM, Hawkey CJ, Cole AT, Balsitis M, Whittle BJ, and Moncada S (1993). Nitric oxide synthase activity in ulcerative colitis and Crohn's disease. Lancet 342:338-340.

Bradley PP, Priebat DA, Christensen RD, and Rothstein G (1982). Measurement of cutaneous inflammation: Estimation of neutrophil content with an enzyme marker. J Invest Dermatol 78:206-209.

Chen F, Lu Y, Castranova V, Rojanasakul Y, Miyahara K, Shizuta Y, Vallyathan V, Shi X, and Demers LM (1999). Nitric oxide inhibits HIV tat-induced NF-kappaB activation. Am J Pathol 155:275-284.

Conner EM, Chen Y, and Grisham MB (2000). Effect of nitric oxide synthase (NOS) inhibition on dextran sulfate sodium (DSS)-induced colitis in rats and mice. Gastroenterology 108:A801.

Cooper HS, Murthy SN, Shah RS, and Sedergran DJ (1993). Clinicopathologic study of dextran sulfate sodium experimental murine colitis. Lab Invest 69:238-249.

Eppihimer MJ, Wolitzky B, Anderson DC, Labow MA, and Granger DN (1996). Heterogeneity of expression of E- and P-selectins in vivo. Circ Res 79:560-569.

Fowler AA, Fisher BJ, Sweeney LB, Wallace TJ, Natarajan R, Ghosh SS, and Ghosh S (1999). Nitric oxide regulates interleukin-8 gene expression in activated endothelium by inhibiting NF-kappaB binding to DNA: Effects on endothelial function. Biochem Cell Biol 77:201-208.

Fraker PJ and Speck JC (1978). Protein and cell membrane iodination with a sparingly soluble chloramine. Biochem Biophys Res Commun 80:849-856.

Gauthier TW, Davenpeck KL, and Lefer AM (1994). Nitric oxide attenuates leukocyte-endothelial interaction via $\mathrm{P}$-selectin in splanchnic ischemia-reperfusion. Am J Physiol 267:G562-G568.

Heinzel FP, Hujer AM, Ahmed FN, and Rerko RM (1997). In vivo production and function of $\mathrm{IL}-12$ p40 homodimers. J Immunol 158:4381-4388.

Henninger DD, Panes J, Eppihimer M, Russell J, Gerritsen M, Anderson DC, and Granger DN (1997). Cytokine-induced VCAM-1 and ICAM-1 expression in different organs of the mouse. J Immunol 158:1825-1832.

Hogaboam CM, Jacobson K, Collins SM, and Blennerhassett MG (1995). The selective beneficial effects of nitric oxide inhibition in experimental colitis. Am J Physiol 268:G673G684.

Huang FP, Niedbala W, Wei XQ, Xu D, Feng GJ, Robinson JH, Lam C, and Liew FY (1998). Nitric oxide regulates Th1 cell development through the inhibition of IL-12 synthesis by macrophages. Eur J Immunol 28:4062-4070.

Kawachi S, Cockrell A, Laroux FS, Gray L, Granger DN, van der Heyde HC, and Grisham MB (1999). Role of inducible nitric oxide synthase in the regulation of VCAM-1 expression in gut inflammation. Am J Physiol 277:G572-G576.
Kubes P and Granger DN (1992). Nitric oxide modulates microvascular permeability. Am J Physiol 262:H611-H615.

Kurose I, Wolf R, Grisham MB, and Granger DN (1994). Modulation of ischemia/reperfusion-induced microvascular dysfunction by nitric oxide. Circ Res 74:376-382.

Lefer AM and Lefer DJ (1999). Nitric oxide. II. Nitric oxide protects in intestinal inflammation. Am J Physiol 276:G572G575.

Lundberg JO, Herulf M, Olesen M, Bohr J, Tysk C, Wiklund NP, Morcos E, Hellstrom PM, Weitzberg E, and Jarnerot G (1997). Increased nitric oxide production in collagenous and lymphocytic colitis. Eur J Clin Invest 27:869-871.

Lyons CR (1995). The role of nitric oxide in inflammation. Adv Immunol 60:323-371.

McCafferty DM, Miampamba M, Sihota E, Sharkey KA, and Kubes P (1999). Role of inducible nitric oxide synthase in trinitrobenzene sulphonic acid induced colitis in mice. Gut 45:864-873.

McCafferty DM, Mudgett JS, Swain MG, and Kubes P (1997). Inducible nitric oxide synthase plays a critical role in resolving intestinal inflammation. Gastroenterology 112:1022-1027.

Middleton SJ, Shorthouse M, and Hunter JO (1993). Increased nitric oxide synthesis in ulcerative colitis. Lancet 341:465-466.

Murohara T, Scalia R, and Lefer AM (1996). Lysophosphatidylcholine promotes $\mathrm{P}$-selectin expression in platelets and endothelial cells: Possible involvement of protein kinase $C$ activation and its inhibition by nitric oxide donors. Circ Res 78:780-789.

Nakamura S, Ohtani H, Watanabe Y, Fukushima K, Matsumoto T, Kitano A, Kobayashi K, and Nagura H (1993). In situ expression of the cell adhesion molecules in inflammatory bowel disease: Evidence of immunologic activation of vascular endothelial cells. Lab Invest 69:77-85.

Neurath MF, Fuss I, Kelsall BL, Stuber E, and Strober W (1995). Antibodies to interleukin 12 abrogate established experimental colitis in mice. J Exp Med 182:1281-1290.

Pfeiffer CJ and Qiu BS (1995). Effects of chronic nitric oxide synthase inhibition on TNB-induced colitis in rats. J Pharm Pharmacol 47:827-832.

Rachmilewitz D, Karmeli F, Okon E, and Bursztyn M (1995b). Experimental colitis is ameliorated by inhibition of nitric oxide synthase activity. Gut 37:247-255.

Rachmilewitz D, Stamler JS, Bachwich D, Karmeli F, Ackerman Z, and Podolsky DK (1995a). Enhanced colonic nitric oxide generation and nitric oxide synthase activity in ulcerative colitis and Crohn's disease. Gut 36:718-723.

Ribbons KA, Zhang XJ, Thompson JH, Greenberg SS, Moore WM, Kornmeier CM, Currie MG, Lerche N, Blanchard J, Clark DA, and Miller MJS (1995) Potential role of nitric oxide in a model of chronic colitis in rhesus macaques. Gastroenterology 108:705-711.

Salas A, Panes J, Rosenbloom CL, Elizalde JI, Anderson DC, Granger DN, and Pique JM (1999). Differential effects of a nitric oxide donor on reperfusion-induced microvascular dysfunction in diabetic and non-diabetic rats. Diabetologia 42: 1350-1358.

Sans M, Panés J, Ardite E, Elizalde Jl, Arce Y, Elena M, Palacin A, Fernandez-Checa JC, Anderson DC, Lobb R, and Piqué JM (1999). VCAM-1 and ICAM-1 mediate leukocyte- 
endothelial cell adhesion in rat experimental colitis. Gastroenterology 116:874-883.

Soriano A, Salas A, Salas A, Sans M, Gironella M, Elena M, Anderson DC, Piqué JM, and Panés J (2000). VCAM-1, but not ICAM-1 or MAdCAM-1, immunoblockade ameliorates DSS-induced colitis in mice. Lab Invest 80:1541-1551.

Spiecker M, Darius H, Kaboth K, Hubner F, and Liao JK (1998). Differential regulation of endothelial cell adhesion molecule expression by nitric oxide donors and antioxidants. J Leukoc Biol 63:732-739.

Stark ME and Szurszewski JH (1992). Role of nitric oxide in gastrointestinal and hepatic function and disease. Gastroenterology 103:1928-1949.

Takahashi M, Ikeda U, Masuyama J, Funayama H, Kano S, and Shimada K (1996). Nitric oxide attenuates adhesion molecule expression in human endothelial cells. Cytokine 8:817-821.
Wallace JL, Vergnolle N, Muscara MN, Asfaha S, Chapman K, McKnight W, Del Soldato P, Morelli A, and Fiorucci S (1999). Enhanced anti-inflammatory effects of a nitric oxidereleasing derivative of mesalamine in rats. Gastroenterology 117:557-566.

Walter UM, Ayer LM, Wolitzky BA, Wagner DD, Hynes RO, Manning AM, and Issekutz AC (1997). Characterization of a novel adhesion function blocking monoclonal antibody to $\mathrm{rat} /$ mouse $\mathrm{P}$-selectin generated in the $\mathrm{P}$-selectin-deficient mouse. Hybridoma 16:249-257.

Whittle BJ (1997). Nitric oxide: A mediator of inflammation or mucosal defense. Eur J Gastroenterol Hepatol 9:1026-1032.

Yamada Y, Marshall S, Specian RD, and Grisham MB (1992). A comparative analysis of two models of colitis in rats. Gastroenterology 102:1524-1534.

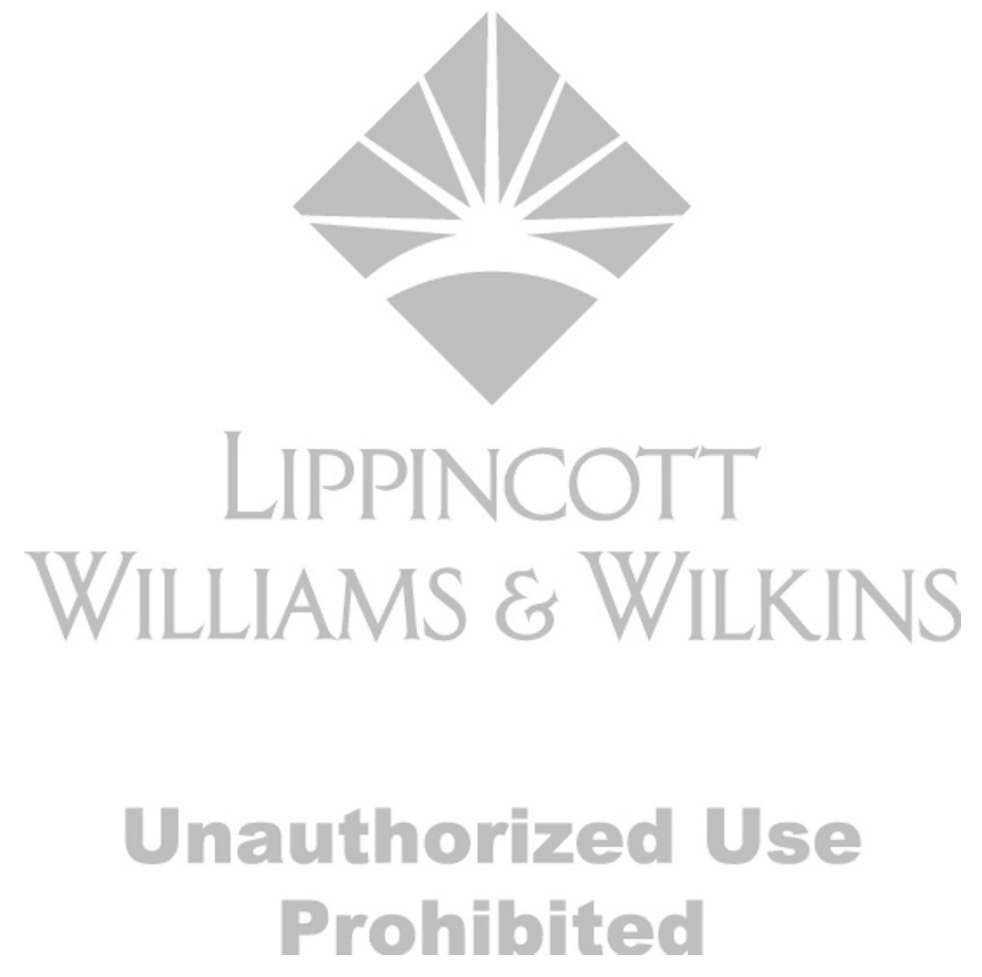

